\title{
ChemComm
}

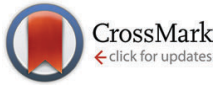

Cite this: Chem. Commun., 2017. 53,2351

Received 25th November 2016, Accepted 31st January 2017

DOI: $10.1039 / \mathrm{c} 6 \mathrm{cc} 09418$

rsc.li/chemcomm

In situ IR spectroscopy is used to monitor electrolyte composition and acid protonation state at the interface of graphene nanoflake electrodes. Deprotonation of both electrode-immobilised and solution acids is driven by a local increase in cation activity at the electrode surface on application of a negative electrode potential.

Degree of acid dissociation $\left(\mathrm{p} K_{\mathrm{a}}\right)$ is a function of solution composition $^{1-3}$ and identity of neighbouring charged species. ${ }^{4,5}$ For example, it is common for acid groups within enzymes to have $\mathrm{p} K_{\mathrm{a}}$ values that vary as a function of local charge in the active site. ${ }^{4}$ Carboxylic acid terminated SAMs have $\mathrm{p} K_{\mathrm{a}}$ values differing by several units from the solution species and values are highly dependent on interactions between neighbouring groups. ${ }^{5}$ Solution composition profoundly alters the $\mathrm{p} K_{\mathrm{a}}$ of Langmuir monolayers of $\mathrm{NH}_{2}$-terminated lipids at the air-water interface, with $\mathrm{p} K_{\mathrm{a}}$ strongly dependent on the ionic strength of the water phase, ranging from 5.1 to 10.5 as the ionic strength increased from 0 to $0.1{ }^{1}$ Protonation states of electrode-immobilized acids are also found to vary with applied potential. ${ }^{2,3,6,7}$ Some studies find that acid association takes place on application of a negative potential and have proposed that protonation is driven by the applied electric field. ${ }^{6,7}$ This electrochemically driven reversible acid protonation reaction has been exploited to fabricate a fast charge-discharge supercapacitor from 3,4,9,10-perylene tetracarboxylic acid adsorbed on graphene layers. ${ }^{8}$ Conversely, other studies have found that deprotonation takes place when a negative potential is applied and is driven by a local increase in cation activity at the electrode interface that lowers the effective $\mathrm{p} K_{\mathrm{a}}$ of the acid groups. ${ }^{2,3} \mathrm{p} K_{\mathrm{a}}$ is defined in terms of acid dissociation but neglects the effect of concomitant interaction of the conjugate base with solution cations. The resulting

Department of Chemistry, University College London, 20, Gordon St., London, WC1H 0AJ, UK. E-mail: k.b.holt@ucl.ac.uk

$\dagger$ Electronic supplementary information (ESI) available: S1-S17: derivation of eqn (1), calculations for Tables 1 and 2, discussion of field induced deprotonation, migration at $+1.0 \mathrm{~V}$, characterization of GNF, GNF-Ca and spectroelectrochemistry cell, spectra in deoxygenated solution and on initial application of $+1.0 \mathrm{~V}$, determination of $\Delta a_{\mathrm{SO}_{4}{ }^{2-}}$. See DOI: $10.1039 / \mathrm{c} 6 \mathrm{cc} 09418 \mathrm{j}$ apparent $\mathrm{p} K_{\mathrm{a}}\left(\mathrm{p} K_{\mathrm{a}}(\mathrm{app})\right)$ can be shown ${ }^{2}(\mathrm{~S} 1, \mathrm{ESI} \dagger)$ to depend on monovalent cation activity $a_{\mathrm{M}}+$ and $K_{\mathrm{as}}$, the equilibrium constant for the association between conjugate base and solution cations, as shown in eqn (1):

$$
\mathrm{p} K_{\mathrm{a}}(\mathrm{app})=\mathrm{p} K_{\mathrm{a}}+\mathrm{p} K_{\mathrm{as}}-\log \left(a_{\mathrm{M}^{+}}\right)
$$

Eqn (1) implies that close to a biased electrode, where $a_{\mathrm{M}^{+}}$ differs from the bulk activity, $\mathrm{p} K_{\mathrm{a}}$ (app) of interfacial species, whether surface-bound or not, should differ from bulk values. Whether a field-induced protonation ${ }^{6-8}$ or cation activity-induced deprotonation $^{2,3}$ mechanism dominates at negative electrode bias will influence performance in applications where control of protonation state of electrode surface acids is paramount. Surface acids are known to influence electron transfer kinetics ${ }^{9,10}$ and capacitive charging ${ }^{6-8}$ at electrodes.

Here we show, using in situ infra-red (IR) spectroelectrochemistry, that a negative electrode potential results in deprotonation of graphene electrode carboxylic acid edge groups. We also observe deprotonation of solution $\mathrm{H}_{3} \mathrm{PO}_{4}, \mathrm{H}_{2} \mathrm{PO}_{4}{ }^{-}$and $\mathrm{HSO}_{4}{ }^{-}$close to the electrode on application of $-0.5 \mathrm{~V}$. We attribute both findings to a decrease in the apparent $\mathrm{p} K_{\mathrm{a}}(\mathrm{app})$ of the acids, in response to a local increase in cation activity at the electrode at negative potential. This observation is important as it implies that speciation of acids near a biased electrode surface can differ significantly from bulk solution and this can be driven purely by cation migration in the absence of adsorption, redox chemistry or $\mathrm{pH}$ change.

Graphene nanoflakes (GNF) are $c a .30 \mathrm{~nm}$ diameter flakes of graphene with a high density of carboxylic acid edge groups (Fig. 1a and Fig. S3, ESI $\dagger$ ). ${ }^{11}$ GNF are highly soluble in water, but addition of $\mathrm{Ca}^{2+}$ results in formation of an insoluble precipitate (GNF-Ca) through complexation of $\mathrm{Ca}^{2+}$ between $-\mathrm{COO}^{-}$groups of neighbouring flakes. IR spectroscopy shows about $20-50 \%$ of the acid groups remain non-complexed (Fig. S3 and Fig. S17, ESI $\dagger$ ). A high surface area electrode was constructed by drop-coating GNF-Ca onto a boron-doped diamond (BDD) electrode (S2, ESI $\dagger$ ). This modified electrode was located above the diamond internal reflectance element of an attenuated total 
(a)

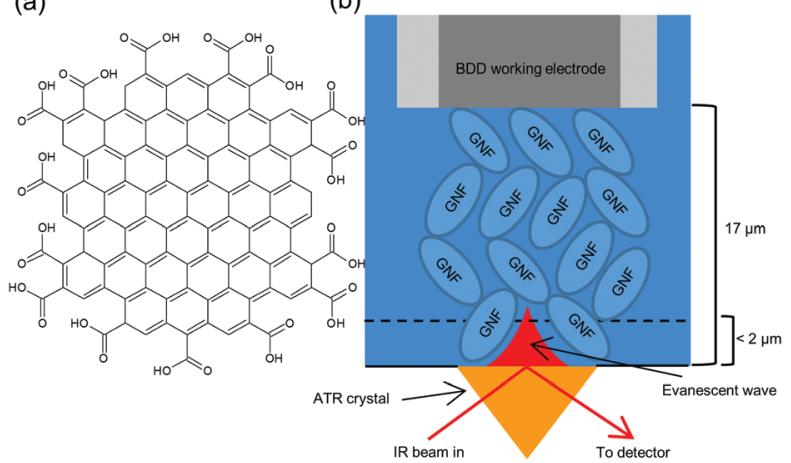

Fig. 1 (a) Cartoon (not to scale) of carboxylic acid edged graphene nanoflake (GNF) used for high surface area electrode; (b) schematic of interfacial region of modified electrode used for in situ IR spectroelectrochemistry.

reflectance (ATR) IR spectrometer (Fig. 1b). The distance between the unmodified BDD electrode and prism was determined as $c a$. $17 \mu \mathrm{m}$ (S4, ESI $\dagger$ ). On immersion in electrolyte the GNF-Ca layer swells (S14, ESI $\dagger$ ), thus the GNF-Ca layer is in direct contact with both prism and electrode. Penetration depth of the IR evanescent wave is $<2 \mu \mathrm{m}$ (S5, ESI $\dagger$ ) hence only the region of GNF-Ca layer furthest from the BDD surface is probed. The high surface area conductive GNF-Ca electrode allows measurement of potentialinduced changes in protonation state of the non-complexed acid edge groups of the GNF-Ca, simultaneously with changes in speciation in the solution at the electrode surface, using in situ IR spectroscopy. Potentials of $+1.0 \mathrm{~V}$ and $-0.5 \mathrm{~V}$ were used, being the limits of electrolyte stability (S9 and S15, ESI $\dagger$ ). All spectra reported are difference spectra. The GNF-Ca layer is intact at the end of experiments, indicating that bound $\mathrm{Ca}^{2+}$ is not perturbed by potential, as migration of $\mathrm{Ca}^{2+}$ would result in loss of the layer due to solubility of the non-complexed GNF.

In $0.1 \mathrm{M} \mathrm{NaCl}$ at $\mathrm{pH} 7$ initial application of $+1.0 \mathrm{~V}$ results in little change in the spectrum relative to a background spectrum recorded without potential (S7, ESI $\dagger$ ); however, subsequent application of $-0.5 \mathrm{~V}$ (Fig. 2, blue) results in decrease in absorbance (losses) at $1755 \mathrm{~cm}^{-1}$ and $1635 \mathrm{~cm}^{-1}$ corresponding to the acid carbonyl $(\mathrm{C}=\mathrm{O})$ stretch and a water bending mode respectively. ${ }^{12}$ Concomitant increases in absorption (gains) are noted at $1570 \mathrm{~cm}^{-1}$ for the carboxylate asymmetric stretch and $1430 \mathrm{~cm}^{-1}$ and $1340 \mathrm{~cm}^{-1}$ for the carboxylate symmetric stretch. The presence of two bands for the symmetric carboxylate stretch is predicted computationally when carboxylate groups occupy different environments within a molecule. ${ }^{13}$ Using the $+0.5 \mathrm{~V}$ spectrum as a background before applying $+1.0 \mathrm{~V}$ results in a mirror image spectral response (Fig. 2, orange); loss of carboxylate stretches at $1570 \mathrm{~cm}^{-1}, 1430 \mathrm{~cm}^{-1}$ and $1340 \mathrm{~cm}^{-1}$ and gain of the $\mathrm{C}=\mathrm{O}$ band and water mode at $1755 \mathrm{~cm}^{-1}$ and $1635 \mathrm{~cm}^{-1}$. Clearly a negative electrode potential induces deprotonation of acids and positive potential results in their re-protonation.

Deprotonation of electrode-immobilized acids has been reported to be induced by applied electric field; ${ }^{6,7}$ however, such a mechanism would result in the opposite trend to that seen here (S8, ESI $\dagger$ ). An increase in interfacial $\mathrm{pH}$ at $-0.5 \mathrm{~V}$ would also induce deprotonation; this could arise through $\mathrm{O}_{2}$,

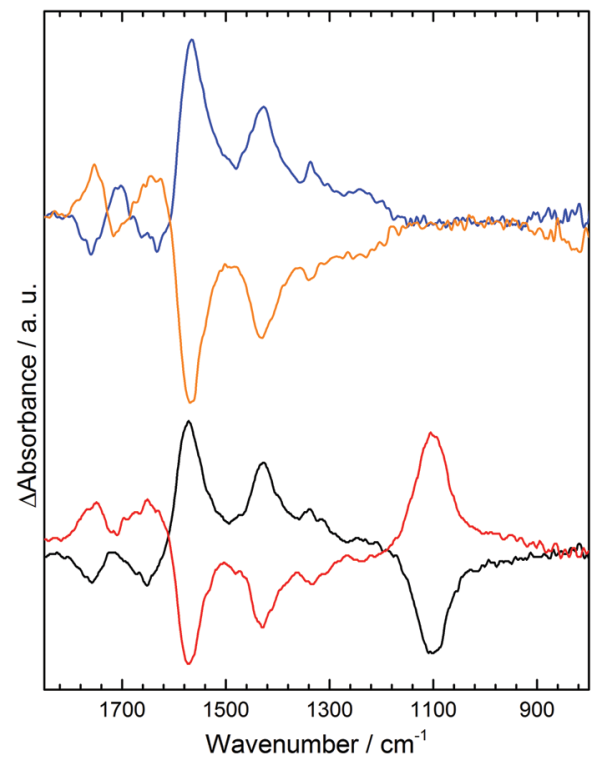

Fig. 2 ATR IR difference spectra of the GNF-Ca modified electrode in $\mathrm{pH}$ 7 solutions: $0.1 \mathrm{M} \mathrm{NaCl},-0.5 \mathrm{~V}$ (blue), $+1.0 \mathrm{~V}$ (orange); $0.1 \mathrm{M} \mathrm{Na}_{2} \mathrm{SO}_{4}$, $-0.5 \vee$ (black), $+1.0 \vee($ red)

$\mathrm{H}^{+}$or water reduction. However, we find identical spectral changes in deoxygenated solution (S6, ESI $\dagger$ ), discounting a $\mathrm{pH}$ change due to $\mathrm{O}_{2}$ reduction. In contrast, spectral changes are completely suppressed when the ionic strength of the electrolyte is lowered while the $\mathrm{pH}$ held constant (S9 and S10, ESI $\dagger$ ). This strong dependence on ion activity is consistent with protonation being due to a negative shift in $\mathrm{p} K_{\mathrm{a}}(\mathrm{app})$ of the acids when local cation activity is increased at the electrode interface at negative potentials, ${ }^{2,3}$ as predicted by eqn (1). This results in deprotonation of some acid groups that would usually remain protonated at $\mathrm{pH} 7$.

Previous titration studies ${ }^{9}$ have shown that the GNF-COOH groups exhibit a wide range of $\mathrm{p} K_{\mathrm{a}}$ values. Despite all edge acids being chemically identical, they occupy different sites and their $\mathrm{p} K_{\mathrm{a}}$ values are strongly influenced by neighboring groups. Below pH 3 most acid edge groups are protonated and above pH 9 they are mostly deprotonated. At intermediate $\mathrm{pH} 7$ some groups are deprotonated while others are not, hence a small negative shift in $\mathrm{p} K_{\mathrm{a}}(\mathrm{app})$ at $-0.5 \mathrm{~V}$ results in the deprotonation of some of these acids, as we observe. Evidence for changes in local ion activity comes from the difference spectra in $\mathrm{pH} 7$ $\mathrm{Na}_{2} \mathrm{SO}_{4}$ (Fig. 2, black, red). Near identical changes to the spectra of the acid $\mathrm{C}=\mathrm{O}$ and carboxylate region in $\mathrm{NaCl}$ are observed, but additionally the asymmetric stretch for the solution sulphate anion ${ }^{14}$ is seen at $1100 \mathrm{~cm}^{-1}$. The anion is repelled from the electrode surface when $-0.5 \mathrm{~V}$ is applied (black) and hence a decrease in absorbance is observed. This demonstrates that a measurable change in local activity of electrolyte ions takes place in response to the electric field at the electrode. Although not detectable with IR, the $\mathrm{Na}^{+}$cation activity must be similarly perturbed, moving in the opposite direction to the sulphate anion. Identical spectral changes are obtained in $0.1 \mathrm{M} \mathrm{pH} 7 \mathrm{~K}_{2} \mathrm{SO}_{4}(\mathrm{~S} 11, \mathrm{ESI} \dagger)$, indicating both cations undergo similar increases in activity at $-0.5 \mathrm{~V}$. 
Calibration with known concentrations of $\mathrm{K}_{2} \mathrm{SO}_{4}$ allows us to estimate that the intensity loss of the sulphate band at $-0.5 \mathrm{~V}$ corresponds to a decrease in $\mathrm{SO}_{4}{ }^{2-}$ concentration of $3.5 \times 10^{-3} \mathrm{~mol} \mathrm{dm}{ }^{-3}(\mathrm{~S} 12, \mathrm{ESI} \dagger)$. We therefore infer from stoichiometry an increase in $a_{\mathrm{K}}+$ of $7 \times 10^{-3}$ at $-0.5 \mathrm{~V}$ (assuming activity coefficients as unity and similar anion and cation mobility). Only negative potentials perturb $a_{\mathrm{SO}_{4}{ }^{2-}}$ from equilibrium values and application of $+1.0 \mathrm{~V}$ does not result in an increase in $a_{\mathrm{SO}_{4}{ }^{2-}}(\mathrm{S} 13, \mathrm{ESI} \dagger)$. This is due to pre-concentration of $7 \times 10^{-3} \mathrm{~mol}$ $\mathrm{dm}^{-3}$ of sulphate within the GNF-Ca electrode structure during initial equilibration in electrolyte (S14, ESI $\dagger$ ), as observed from the IR spectrum of the equilibrated electrode. Thus migration of sulphate towards the electrode at $+1.0 \mathrm{~V}$ must take place against a concentration gradient and is disfavoured. Migration of sulphate away from the electrode is found to be dependent on the magnitude of negative potential applied (S15, ESI $\dagger$ ).

Repetition of experiments at pH 3.5 (Fig. 3) shows that in $\mathrm{KCl}$ and $\mathrm{K}_{2} \mathrm{SO}_{4}$ changes to the electrode acid group spectra are almost identical to those in $\mathrm{NaCl}$ and $\mathrm{Na}_{2} \mathrm{SO}_{4}$ at $\mathrm{pH}$ 7. This is consistent with GNF acid groups having $\mathrm{p} K_{\mathrm{a}}$ values of 3 to 9 and hence some being able to undergo deprotonation at $\mathrm{pH} 3.5$ in response to increased $a_{\mathrm{K}}+$. In $\mathrm{K}_{2} \mathrm{SO}_{4}$ the sulphate band also shows the same response to applied potential as at $\mathrm{pH} 7$, although the absorbance changes are weaker and broader. At pH 3 (Fig. 3 black, red) spectral changes for GNF acid groups and solution sulphate are much lower in intensity. For the acid groups this is unsurprising, as only a small number of the most acidic groups can undergo deprotonation at this $\mathrm{pH}$ as few have a $\mathrm{p} K_{\mathrm{a}}$ of 3 or below. Spectral changes in the sulphate region can be rationalized by predicting trends in interfacial activities of

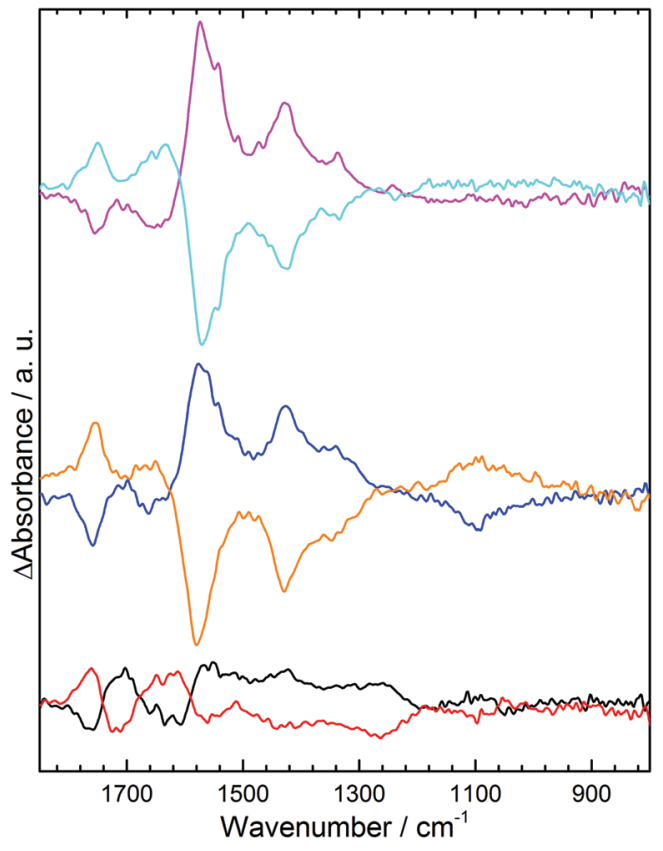

Fig. 3 ATR IR difference spectra of the GNF-Ca modified electrode interface in: $0.1 \mathrm{M} \mathrm{pH} 3.5 \mathrm{KCl},-0.5 \mathrm{~V}$ (pink), $+1.0 \mathrm{~V}$ (light blue); $0.1 \mathrm{M} \mathrm{pH}$ $3.5 \mathrm{~K}_{2} \mathrm{SO}_{4},-0.5 \mathrm{~V}$ (blue), $+1.0 \mathrm{~V}$ (orange); $0.1 \mathrm{M} \mathrm{pH} 3 \mathrm{~K}_{2} \mathrm{SO}_{4},-0.5 \mathrm{~V}$ (black), $+1.0 \vee($ red)
Table 1 Predicted changes in activity of $\mathrm{HSO}_{4}{ }^{-}$and $\mathrm{SO}_{4}{ }^{2-}$ on application of $-0.5 \mathrm{~V}$ calculated from eqn (1)

\begin{tabular}{llllcc}
\hline $\mathrm{pH}$ & $E / \mathrm{V}$ & $a_{\mathrm{K}^{+}}{ }^{a}$ & $\mathrm{p} K_{\mathrm{a}}(\mathrm{app}) \mathrm{HSO}_{4}{ }^{-b}$ & $\Delta a_{\mathrm{HSO}_{4}} / 10^{-3 c}$ & $\Delta a_{\mathrm{SO}_{4}{ }^{2-}} / 10^{-3 c}$ \\
\hline 7 & - & 0.200 & 2.619 & 0 & 0 \\
7 & -0.5 & 0.207 & 2.604 & 0 & 0 \\
3.5 & - & 0.198 & 2.623 & 0 & 0 \\
3.5 & -0.5 & 0.205 & 2.608 & -0.4 & +0.4 \\
3 & - & 0.192 & 2.637 & 0 & 0 \\
3 & -0.5 & 0.199 & 2.621 & -0.8 & +0.8
\end{tabular}

${ }^{a}$ See S16 (ESI) for calculation of $a_{\mathrm{K}}+{ }^{b}$ From eqn (1) with $\mathrm{p} K_{\mathrm{a}}\left(\mathrm{HSO}_{4}{ }^{-}\right)=$ 1.92, $\mathrm{p} K_{\mathrm{as}}=0 .{ }^{c}$ From $\mathrm{p} K_{\mathrm{a}}(\mathrm{app})$ and Henderson-Hasselbalch eq.

solution species in response to changes in $a_{\mathrm{M}^{+}}$at the electrode. Using the value for $\Delta a_{\mathrm{K}}+$ of $7 \times 10^{-3}$ at $-0.5 \mathrm{~V}$, determined above, eqn (1) can be used to calculate $\mathrm{p} K_{\mathrm{a}}$ (app) for $\mathrm{HSO}_{4}{ }^{-}$with no applied potential and at $-0.5 \mathrm{~V}$, as shown in Table 1 . Changes in sulphate and $\mathrm{HSO}_{4}{ }^{-}$activity resulting from the change in $\mathrm{p} K_{\mathrm{a}}(\mathrm{app})$, have been calculated at different $\mathrm{pH}$ using the Henderson-Hasselbalch equation (S16, ESI $\dagger$ ). At $\mathrm{pH} 7$, $\mathrm{SO}_{4}{ }^{2-}$ activity is unperturbed by any change in $\mathrm{p} K_{\mathrm{a}}(\mathrm{app})$, hence the spectral changes to the sulphate band result only from migration of the anion away from the electrode at $-0.5 \mathrm{~V}$.

At $\mathrm{pH} 3.5$, as the solution $\mathrm{pH}$ is closer to $\mathrm{p} K_{\mathrm{a}}$ (app) values, deprotonation of $0.4 \times 10^{-3} \mathrm{~mol} \mathrm{dm}^{-3}$ of $\mathrm{HSO}_{4}{ }^{-}$is predicted at $-0.5 \mathrm{~V}$. Spectral bands for $\mathrm{HSO}_{4}{ }^{-}$span ca. $850-1250 \mathrm{~cm}^{-1}$, hence a decrease in intensity is predicted over this spectral range ${ }^{14}$ however, this will be concomitant with an increase in intensity centered at $1100 \mathrm{~cm}^{-1}$ as the sulphate activity is increased. Overall spectral changes in the sulphate region are therefore predicted to be very weak at $\mathrm{pH} 3.5$, due to the simultaneous increase and decrease in absorbance over this wavenumber range, and broader than at $\mathrm{pH} 7$ due to the contribution from $\mathrm{HSO}_{4}{ }^{-}$ which exhibits bands over a wider range than $\mathrm{SO}_{4}{ }^{2-}$. This analysis broadly fits with experimental results (Fig. 3 blue), where a weaker and broader band is observed in this region compared to $\mathrm{pH} 7$ (Fig. 2 black). An overall loss in intensity is still observed for both species, as the above analysis ignores the electrostatic migration of anionic species away from the electrode. This results in a larger observed loss in spectral intensity for both species than predicted by Table 1. The effect of the shift in $\mathrm{p} K_{\mathrm{a}}$ (app) for $\mathrm{HSO}_{4}{ }^{-}$at $-0.5 \mathrm{~V}$ is seen more strongly at $\mathrm{pH} 3$, where the gain in $\mathrm{SO}_{4}{ }^{2-}$ and loss of $\mathrm{HSO}_{4}{ }^{-}$is predicted to be greater (Table 1). Although the spectral bands in the sulphate region (Fig. 3 black) are almost non-existent, due to cancelling of the increase in $\mathrm{SO}_{4}{ }^{2-}$ by the decrease in $\mathrm{HSO}_{4}{ }^{-}$at similar wavenumbers, we do now observe a small gain of sulphate at $1100 \mathrm{~cm}^{-1}$ along with a small loss of $\mathrm{HSO}_{4}{ }^{-}$at $1050 \mathrm{~cm}^{-1}$, in line with predicted trends.

The same analysis (S16, ESI $\dagger$ ) can be carried out to predict spectral changes in $0.1 \mathrm{M}$ phosphate solutions at $-0.5 \mathrm{~V}$, as shown in Table 2 for calculated changes in activities for $\mathrm{H}_{3} \mathrm{PO}_{4}$, $\mathrm{H}_{2} \mathrm{PO}_{4}{ }^{-}$and $\mathrm{HPO}_{4}{ }^{2-}$ at $\mathrm{pH} \mathrm{3,} 7$ and 9. The experimental spectra obtained under these conditions are shown in Fig. 4. At $\mathrm{pH} 3$ Table 2 predicts significant losses in spectral intensity for $\mathrm{H}_{3} \mathrm{PO}_{4}$ species $^{15}$ at 1172, 1005 and $889 \mathrm{~cm}^{-1}$ with gains at 1159, 1077,940 and $875 \mathrm{~cm}^{-1}$ for $\mathrm{H}_{2} \mathrm{PO}_{4}{ }^{-}$. This is broadly observed in the experimental spectrum (Fig. 4 black), where a particularly 
Table 2 Changes in activity of $\mathrm{H}_{3} \mathrm{PO}_{4}, \mathrm{H}_{2} \mathrm{PO}_{4}{ }^{-}$and $\mathrm{HPO}_{4}{ }^{2-}$ on application of $-0.5 \mathrm{~V}$ calculated from eqn (1)

\begin{tabular}{lllll}
\hline $\mathrm{pH}$ & $E / \mathrm{V}$ & $\Delta a_{\mathrm{H}_{3} \mathrm{PO}_{4}} / 10^{-3}$ & $\Delta a_{\mathrm{H}_{2} \mathrm{PO}_{4}}-110^{-3}$ & $\Delta a_{\mathrm{HPO}_{4}{ }^{2-}} / 10^{-3}$ \\
\hline 3 & -0.5 & -2.0 & +2.0 & 0 \\
7 & -0.5 & 0 & -0.4 & +0.4 \\
9 & -0.5 & 0 & -0.2 & +0.2
\end{tabular}

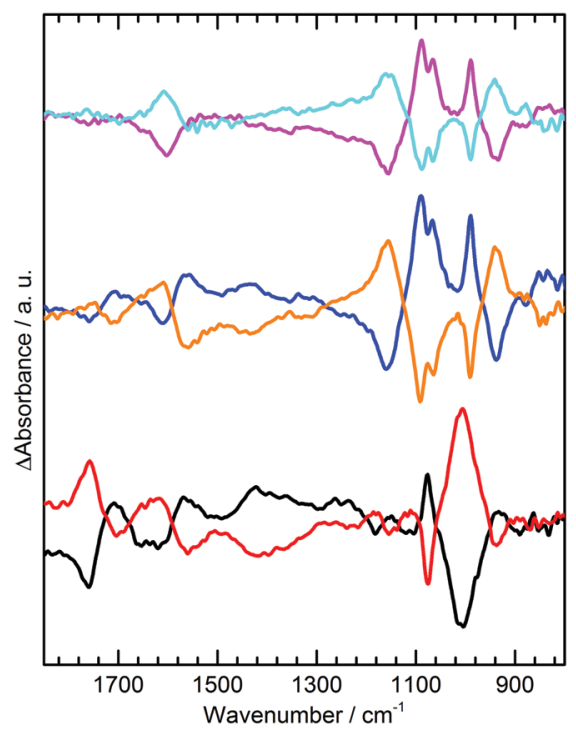

Fig. 4 ATR IR difference spectra of the GNF-Ca modified electrode interface in: $0.1 \mathrm{M} \mathrm{pH} 3 \mathrm{H}_{3} \mathrm{PO}_{4} / \mathrm{KH}_{2} \mathrm{PO}_{4},-0.5 \mathrm{~V}$ (black), $+1.0 \mathrm{~V}$ (red); $0.1 \mathrm{M} \mathrm{pH} 7 \mathrm{KH}_{2} \mathrm{PO}_{4} / \mathrm{K}_{2} \mathrm{HPO}_{4},-0.5 \mathrm{~V}$ (blue), $+1.0 \mathrm{~V}$ (orange); $0.1 \mathrm{M} \mathrm{pH} 9.2$ $\mathrm{K}_{2} \mathrm{HPO}_{4},-0.5 \mathrm{~V}$ (pink), $+1.0 \mathrm{~V}$ (light blue).

strong absorption loss is seen at $1005 \mathrm{~cm}^{-1}$ for $\mathrm{H}_{3} \mathrm{PO}_{4}$, along with a gain at $1077 \mathrm{~cm}^{-1}$ for $\mathrm{H}_{2} \mathrm{PO}_{4}{ }^{-}$, although as some gain bands are in similar positions to losses they cancel each other out. At both $\mathrm{pH} 7$ and $9 \mathrm{H}_{2} \mathrm{PO}_{4}{ }^{-}$is predicted to undergo deprotonation to give $\mathrm{HPO}_{4}{ }^{2-}$. Experimentally, at $\mathrm{pH} 7$ and 9 clear gains are observed at 1078 and $990 \mathrm{~cm}^{-1}$ corresponding to increased $\mathrm{HPO}_{4}{ }^{2-}$. The apparent splitting of the $1078 \mathrm{~cm}^{-1}$ band is due to simultaneous decrease in absorbance at $1077 \mathrm{~cm}^{-1}$, which along with losses at 940 and $1155 \mathrm{~cm}^{-1}$ indicates concomitant loss of $\mathrm{H}_{2} \mathrm{PO}_{4}{ }^{-}$, exactly as predicted.

However, comparison of the predicted changes in Table 2 with Fig. 4 show that the experimental phosphate difference bands are significantly more intense than predicted at $\mathrm{pH} 7$ and 9. The intense phosphate bands are in contrast to anomalously weak acid carbonyl and carboxylate bands under the same conditions. In $\mathrm{NaCl}$ and $\mathrm{Na}_{2} \mathrm{SO}_{4}$ at $\mathrm{pH} 7$ the acid spectral changes are prominent and of a similar magnitude to those at $\mathrm{pH}$ 3.5. This anomalous behavior is attributed to suppression of $\mathrm{COOH}$ deprotonation in response to changes in phosphate speciation. With a local increase in cation activity, the $\mathrm{p} K_{\mathrm{a}}(\mathrm{app})$ of $\mathrm{H}_{2} \mathrm{PO}_{4}{ }^{-}$is lowered and deprotonation takes place:

$$
\mathrm{H}_{2} \mathrm{PO}_{4}^{-} \rightarrow \mathrm{HPO}_{4}{ }^{2-}+\mathrm{H}^{+}
$$

In response to the resulting decrease in $\mathrm{pH}$, deprotonation of the acid edge groups is suppressed and protonation favoured:

$$
\mathrm{GNF}-\mathrm{COO}^{-}+\mathrm{H}^{+} \rightarrow \mathrm{GNF}-\mathrm{COOH}
$$

Thus at $-0.5 \mathrm{~V}$, although the local increase in $a_{\mathrm{M}^{+}}$favours deprotonation of GNF-COOH, the simultaneous decrease in $\mathrm{pH}$ caused by phosphate deprotonation drives protonation of GNF-COO ${ }^{-}$. These competing influences lead to the observed anomalously small overall changes in the acid group spectral bands. Consumption of protons in eqn (3) encourages further deprotonation of $\mathrm{H}_{2} \mathrm{PO}_{4}{ }^{-}$and results in the unexpectedly intense phosphate spectral bands. These bands are less intense at $\mathrm{pH} 9$ as the consumption of protons by $\mathrm{GNF}^{-\mathrm{COO}^{-}}$is less favoured at the higher $\mathrm{pH}$. Thus unexpectedly, these spectra show that the electrode acid groups act as a buffer to changes in phosphate ionization, rather than the solution species buffering changes to the electrode acid groups.

The ubiquity of acid moieties at electrode interfaces, as defect sites on carbon electrodes and as polymer electrolytes of solid supercapacitors, makes understanding their response to applied electrode potential an essential area of study. Here we have shown using in situ IR spectroscopy that both electrodeimmobilized and solution acids undergo deprotonation in response to increased cation activity at a negatively biased electrode. This observation will allow design of electrodes with specific potential-dependent protonation behaviour, which can be tuned by matching with appropriate electrolyte species.

We thank C. G. Salzmann for GNF samples and EPSRC EP/J010006/1 for funding.

\section{Notes and references}

1 K. Ariga, T. Nakanishi, J. P. Hill, M. Shirai, M. Okuno, T. Abe and J. Kikuchi, J. Am. Chem. Soc., 2005, 127, 12074.

2 K. Sugahara, K. Shimazu and K. Uosaki, Langmuir, 2000, 16, 7101.

3 A. M. Luque, A. Cuestra, J. J. Calvente and R. Andreu, Electrochem. Commun., 2014, 45, 13.

4 J. H. Bradbury and J. A. Carver, Biochemistry, 1984, 23, 4905.

5 O. Gershevitz and C. N. Sukenik, J. Am. Chem. Soc., 2004, 126, 482.

6 C. P. Smith and H. S. White, Langmuir, 1993, 9, 1.

7 I. Burgess, B. Seivewright and R. B. Lennox, Langmuir, 2006, 22, 4420.

8 S. Gan, L. Zhong, L. Gao, D. Han and L. Niu, J. Am. Chem. Soc., 2016, 138, 1490.

9 M. M. Lounasvuori, M. Rosillo-Lopez, C. G. Salzmann, D. J. Caruana and K. B. Holt, Faraday Discuss., 2014, 172, 293.

10 L. A. Hutton, J. G. Iacobini, E. Bitzion, R. B. Channon, M. E. Newton and J. V. Macpherson, Anal. Chem., 2013, 85, 7230.

11 M. Rosillo-Lopez, T. J. Lee, M. Bella, M. Hart and C. G. Salzmann, RSC Adv., 2015, 5, 104198.

12 G. Socrates, Infrared and Raman Characterisation Frequencies, John Wiley and Sons, 2001.

13 T. Kar, S. Scheiner, U. Adhikari and A. K. Roy, J. Phys. Chem. C, 2013, 117, 18206.

14 K. L. Nash, J. Sully and A. B. Horn, Phys. Chem. Chem. Phys., 2000, 2, 4933.

15 E. J. Elzinga and D. L. Sparks, J. Colloid Interface Sci., 2007, 308, 53. 